\title{
Lathosterol and Noncholesterol Sterols in Routine Use for the Differentiation and Monitoring of Dietary and Drug Induced Treatment of Hypercholesterolemias in Children and Adolescents
}

\author{
Josef Hyanek ${ }^{1,{ }^{*}}$, Frantisek Pehal ${ }^{2}$, Ladislava Dubska ${ }^{2}$, Vera Martinikova $^{1}$, Jana Privarova ${ }^{1}$ \\ and Ludek Taborsky ${ }^{2}$
}

\author{
${ }^{1}$ Lipid Outpatient Cliníc; ${ }^{2}$ Department of Clinical Biochemistry, Hematology and Immunology, Na Homolce \\ Hospital, Prague, (Nemocnice Na Homolce, Roentgenova 2, 15030 Praha 5), Czech Republic
}

\begin{abstract}
Aims: The authors discuss their 15 years of experience with use of noncholesterol sterols (NCS) when diagnosing heterozygous familial hypercholesterolemia (HFH) and the dietary and drug treatment of children and adolescents when lathosterol (Lat) and desmosterol (Des) as cholesterol synthesis precursors, and campesterol (Cam) and sitosterol (Sit) as cholesterol absorption precursors are included.

Patients and Methods: 38 children and adolescents (6-18 yrs) with HFH proven by molecular genetic testing of LDLcholesterol receptor deficit; 107 children patients with clinical and laboratory symptoms of other hypercholesterolemias; 84 healthy school-age children as a control group. Routine lipid spectrum scan-total cholesterol (TCh), LDL-Ch, HDLCh, TAG, with additional apo A1, apo B, Lp (a), LDL-receptors, apo E polymorphism; Lat, Des, Cam and Sit in the plasma-was established by means of GC/MS.

Results: The HFH patients on a low cholesterol diet (LCHD) who come to our lipid outpatient clinic have elevated levels of Lat and Des, unlike patients with alimentary hypercholesterolemia $(p<0,001)$. Lat and Des levels are high following interruption of medical treatment during long vacations or when drug treatment is neglected. Administration of statins only in sufficiently high therapeutic doses reduces Lat and Des $(p<0,001)$. Compensatory elevation of Cam and Sit occurs only in few pediatric patients. Ezetimibe decreases Cam and Sit more efficiently than Lat or Des. Combination of statin with ezetimibe is most efficient in decrease of not only TCh but also Lat and Des, as well as Cam and Sit.
\end{abstract}

Conclusions: Extending the laboratory spectrum by precursors of cholesterol synthesis and absorption improves the differential diagnosis of $\mathrm{HFH}$ and makes monitoring and/or treatment of children and adolescents more precise.

Keywords: Noncholesterol sterols, lathosterol, desmosterol, campesterol, sitosterol, phytosterols, heterozygous familial hypercholesterolemia, statins, ezetimibe, dietary and drug treatment.

\section{INTRODUCTION}

All patients suffering from inherited hypercholesterolemias are burdened by premature cardio- or cerebrovascular events. Early identification of these inherited diseases allows administration of proper lifestyle and drug therapy as early as in childhood to prevent cardiovascular or cerebrovascular complications [1-4]. There exist 2 types of disorders characterized by marked elevation of total cholesterol (TCh) and LDL-cholesterol (LDL-Ch): (1) familial hypercholesterolemias resulting from deficient LDL receptor proteins that cannot a) bind LDL (binding defects), b) internalize LDL (internalizing defects), c) disrupt the normal recycling of the LDLR (recycling defects), and (2) familial ligand defect of B-100 (FDB) hypercholesterolemia with missence mutation R3500Q.

It is a well-known fact that heterozygous familial hypercholesterolemia (HFH) with autosomal dominant

${ }^{*}$ Address correspondence to this author at the Lipid Outpatient Clinic, Hospital Homolka, Prague (Ambulance pro poruchu lipidového metabolizmu, Nemocnice Na Homolce, Roentgenova 2, 15030 Praha 5), Czech Republic; Tel:+420 603440 013; E-mail: josef.hyanek@homolka.cz

E-ISSN: $1929-5634 / 14$ mode of inheritance (OMIM 143890) cannot be successfully treated by even a strict low-cholesterol diet (LCHD), and requires differentiated drug therapy. Recently, it has been finally accepted that pediatric $\mathrm{HFH}$ (boys from the age of 10 years and girls after first menstruation) require the same intensity of medical therapy as adults [5-10].

However, what are our options for early distinction between the so called "alimentary hypercholesterolemia" $(\mathrm{AH})$ caused by overeating and an unhealthy lifestyle, which is most frequently encountered in our lipid clinic, and the most severe forms of HFH? The clinical symptoms in children being not yet as sufficiently developed as in adults, we can only use typical laboratory findings from the lipid spectrum supported by the molecular genetic examination of LDL-cholesterol receptors. Over the past 15 years, we have included noncholesterol sterols (NCS) in the testing, such as surrogate of cholesterol synthesis precursors and surrogate for cholesterol absorption in the testing.

Following the introduction of compulsory nationwide selective screening for hyperlipoproteinemia in the 

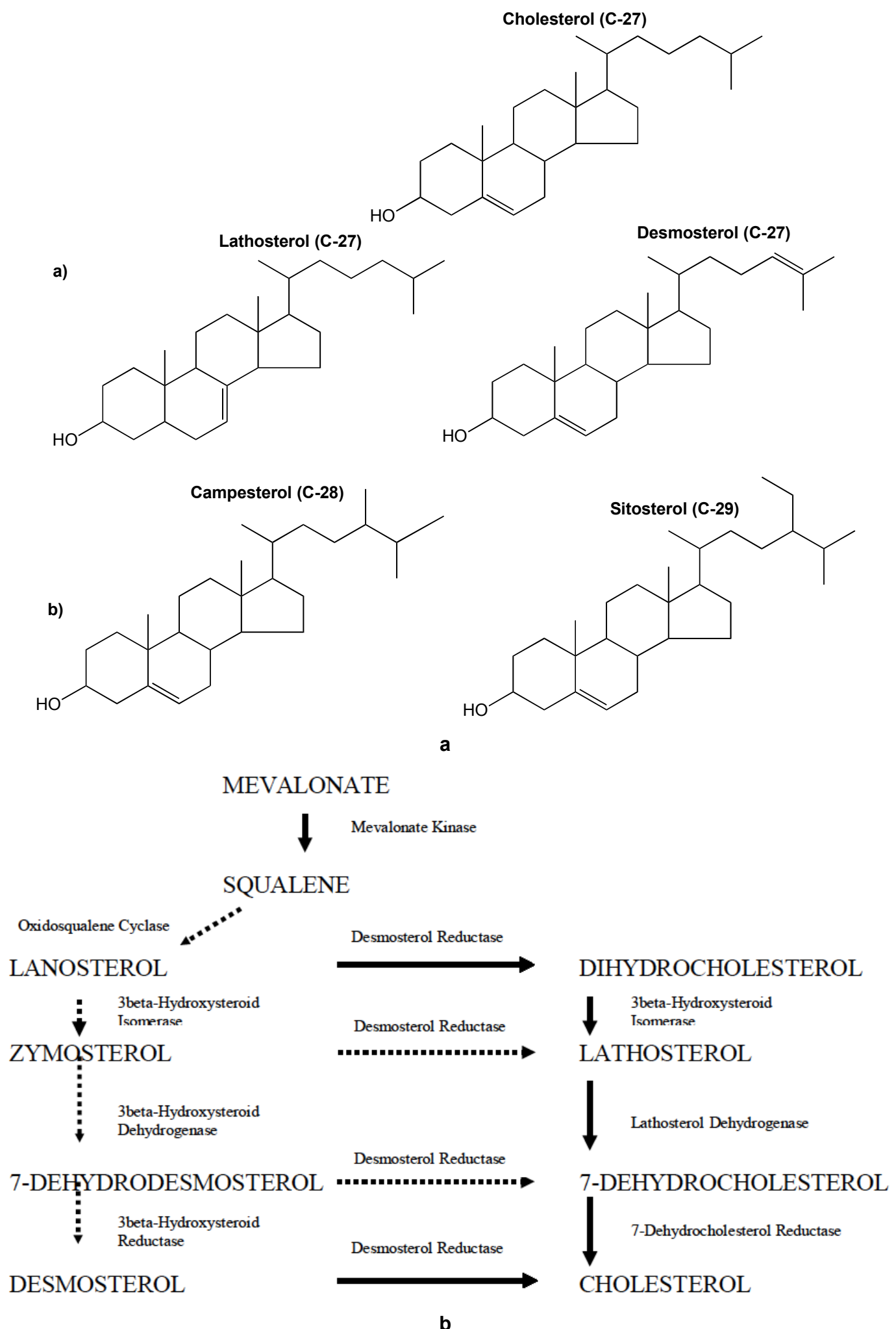

b

Figure 1: a) Structures of cholesterol, its most important precursors and some phytosterols.

b) Simplified metabolism of cholesterol synthesis.

Czech Republic for children from high-risk families in their fifth and thirteenth year of life (since 1994), it is not only children of patients operated on in our hospital with a surgically documented risk of CVD who come to our metabolic clinic for further examination, but primarily children who have been identified with a range of different hypercholesterolemia symptoms in pediatric primary care settings [11]. These symptoms 
are subsequently differentiated and the required therapy is determined depending on the results-either $\mathrm{LCHD}$ in cases of $\mathrm{AH}$ or drug treatment in cases of $\mathrm{HFH}$. Encouraged by the pioneering work of Hamilton, Miettinen, Kempen, Jones, Gylling [12-20], and the promising latest research outcomes [21-23], we have attempted to combine the standard lipid marker examination with the most easily available markers of cholesterol synthesis precursors-lathosterol (Lat) and desmosterol (Des)-, and the cholesterol absorption markers-campesterol (Cam) and beta-sitosterol (Sit) - for better hypercholesterolemia differentiation. (for NCS structures and simplified metabolism scheme see Figure 1a, b).

From a large cohort of pediatric and adolescent patients classified into groups according to the etiology of their hypercholesterolemia, we have till now observed important diagnostic and therapeutic dependencies sometimes similar to observations of Noto et al. or Hedman et al., which are presented below [24, 25].

\section{PATIENTS DEFINITION AND METHODS}

Out of 1,000 patients regularly attending our lipid clinic, the following were selected for the study:

- $\quad 38$ statin and ezetimibe treated children (10-18 yrs) with a positive family history of CVD (Framingham Risk Score 10-20\%) and the molecular genetically proved deficit of LDLreceptor mutations, specifically in p.Gly592Glu (8 patients), p. Cys200Tyr (2 patients), p. Pro424_Asn425ins32 (2 patients), p. Gly218del (2 patients), p. Arg4+6Trp (1 patient), p. Asp266Glu (1 patient), p. Gly396Alafsx54 (1 patient), p. Ser177Leu (1 patient), p. Trp 666X (I patient), p. His690ThrfsX19 (1 patient), p. Cys143Arg (1 patient), p. Asp227Glu (1 patient), p. Gly149Cys (1 patient), p. Gly176Val (1 patient), p. Ala299Val (1 patient), Ala
232Asn27+del (1 patient); and with the familial ligand-defective apoB 100 (FDB) 3500W mutation (1 homozygote patient and 11 heterozygote patients);

- $\quad 107$ statin, ezetimibe or LCHD treated children of the same age with metabolic findings resembling $\mathrm{HFH}$, where molecular genetic analysis has not yet confirmed LDL-R deficiency (familial combined hyperlipidemia, polygenic hypercholesterolemia);

- $\quad 84$ healthy school-age children and adolescents (6-18 years old) from schools in Prague area as a control group;

- $\quad 37$ children of the same age with confirmed "alimentary hypercholesterolemia", frequently accompanied by variously presented hypertriglyceridemia and obesity;

- 35 randomly selected healthy blood donors (1860 years old) as a control group for NCS of healthy adults.

The basic characteristics of the cohorts investigated are shown in Table 1.

The LCHD was defined as 1992 NCEP-Ped Step II diet ( $<300 \mathrm{mg} / \mathrm{d}$ cholesterol in natural food) [26]. The "Alimentary Hypercholesterolemia" was determined on the basis of a lipid spectrum assessment, pedigree analysis, low risk of CVD in the family, and evaluation of a submitted two-week food journal, which was analyzed for nutrient content and cholesterol intake (mg/d) by the Ostrasoft Co. (1992) software programme [27]. According to recommendations by Rifkind, deJong, and Wiegman [5, 6, 28], individual cholesterol tolerance was respected so as for TCh blood levels not to increase over $4.8 \mathrm{mmol} / \mathrm{l}$.

Medical treatment involves the use of simvastatinZocor (MSD) in individual doses of $5-20 \mathrm{mg} / \mathrm{d}-$, which has been successfully combined with ezetimibe-

Table 1: Basic Characteristic of Investigated Groups of Healthy Children, Healthy Adults and Child Patients Suffering from Hypercholesterolemias

\begin{tabular}{|c|c|c|c|c|c|c|}
\hline & Age (yrs) & Women/Men & Skin Fold (mm) & BMI & $\mathrm{TCh}(\mathrm{mmol} / \mathrm{l})$ & Apo-B (g/l) \\
\hline 48 Children on LCHD & 10 to 18 & $25 / 23$ & $5.5 / 10.2 / 8.9$ & & 6.7 & 1.86 \\
\hline 38 Children on Statins & 10 to 18 & $25 / 23$ & $5.5 / 10.2 / 8.9$ & & 5.4 & 1.56 \\
\hline 84 Healthy Children & 6 to 18 & $52 / 32$ & $4.2 / 8.5 / 7.5$ & & 3.7 & 1.12 \\
\hline 35 Healthy Adults & 20 to 65 & $12 / 13$ & & 28.1 & 5.2 & 1.52 \\
\hline
\end{tabular}


Ezetrol (MSD) in individual doses of $5-10 \mathrm{mg} / \mathrm{d}$ - over the past 10 years $[5,6,9,10]$. During the two-month summer vacations, when the patients are usualy not available for monitoring and drug therapy, the drug treatment is often insufficiently observed, and the only remaining treatment is $L C H D$.

Monitoring of the diet and drug treatment is ensured by biochemical and immunological testing of lipid markers at 3-6 month intervals (depending on tha patient's compliance); levels of NCS, lipid soluble vitamins, sex hormones and trace elements in 6-month intervals. Height and weight are recorded using a software programme, secondary signs of sex maturation are registered according to Tanner and Goldstein [29] on each visit to the clinic. Performed annually, skinfold measurements are taken by the Best caliper, and IMT is measured using a VigmedSound device.

The routine biochemical and classical lipid spectrum (TCh colorimetric assay, HDL immunoassay, LDL direct immunoassay, TAG enzymatically) is determined using a Synchron Beckman Coulter LX 20; haematological spectrum by means of an Advia 120 Bayer; apo Al and apo B nephelometrically using an Immage; apo $\mathrm{E}$ polymorphism is measured by molecular genetic analysis; sexual hormone levels are determined with the IRMA method using a Stratec SR300; trace elements using a GT-AAS Varian; lipid soluble vitamins by means of HPLC with UV detection; vitamin $\mathrm{D}_{3}$ with the RIA technique using a Multicrystal Berthold LB211; vitamin B6 using a Chromsystem; holotranscobalamin using an Abbot AXIM; and betacarotene by means of HPLC.

The following DNA analyses of genes for LDLreceptors and FDB (familial ligand-defective $A p o B$ ) are performed: direct DNA analysis, sequential analysis of exon 4 and 5 , and analysis of deletions and duplications of the LDL-R gene and the entire region using the Multiplex Ligation Probe Amplification method, carried out through the goodwill of the Genetic Laboratory, Centre of Cardiovascular and Transplantation Surgery, Brno (MedPed project Czech National Coordinator, MUDr. T. Freiberger, PhD.) [30]. PCSK9 genes are not sequenced. The first degree relatives of $\mathrm{HFH}$ probands with identified gene mutations undergo DNA sequencing regardless of the LDL-cholesterol plasma levels.

Plasma NCS were determined first by GC following Phillips et al. [31], later using the Theunissen [32] modification by means of a GC/MS Finnigan Mat 120B: internal standard epicoprostenal, CV $<10 \%$. The values of detectable lanosterol are very low without any possible diagnostic use. According to our practical experience and a longitudinal evaluation of the NCS levels, Des essentially follows in lower concentrations the Lat values, and Sit follows Cam values in a similar way: we have retained only these two markers in routine testing over the recent years and found them to be sufficient to register both cholesterol synthesis and phytosterol absorption.

The overall lipid extraction from the serum samples was performed using the Folch method [44]. First, the inner standard of epicholesterol $(5 \mu \mathrm{g})$ was added to the serum sample $(0.9 \mathrm{ml})$. Methanol $(0.9 \mathrm{ml})$ was added, and the whole mixture was agitated for 15 minutes. The extraction was done using chloroform $(2 \mathrm{x}$ $0.9 \mathrm{ml}$ ) while adding water solution of $\mathrm{NaCl}$. The mixture was then centrifuged (at $200 \mathrm{~g}$ ) for 10 minutes.

The lipid saponification was performed using the modified Thompson and Merola method [45]. Following evaporation of chloroform ethanol with $3 \%$ pyrogalol $(8 \mathrm{ml})$ was added to the lipid extract sample. The preparation was briefly mixed by hand, and $\mathrm{KOH}(0.5$ $\mathrm{ml}, 1.28 \mathrm{~g} / \mathrm{ml}$ ) solution was added. The saponification (30 min. at $88^{\circ} \mathrm{C}$ ) was performed following mixing and sonification of each sample. Cyclohexan $(20 \mathrm{ml})$ and distilled water $(12 \mathrm{ml})$ were added to each sample and the content was agitated. After centrifugation (at $200 \mathrm{~g}$ ) the upper layer of cyclohexan was transferred into a vial, and evaporated under a nitrogen stream (approx. $\left.65^{\circ} \mathrm{C}\right)$

Another step in the preparation of samples for GC/MS was their extraction derivatization using methanol-methyl chloroformate-pyridine. The reason was derivatization of sterols while separating the neutral lipid fraction from polar lipids. The derivatization was performed using the modified Hušek Method [46].

The extracted compounds were then analysed on the Focus GC with ITQ 700 ion trap mass spectrometer (manufactured by Thermo Electron Corporation) heated to $200^{\circ} \mathrm{C}$. TR-1 column $(30 \mathrm{~m}$ length, $0.25 \mathrm{~mm}$ internal diameter, $0.25 \mu \mathrm{m}$ film of dimethyl polysiloxane) was used for separation. The ion source was operated in the electron ionisation mode $(70 \mathrm{eV}$, $20 \mu \mathrm{A}$ ) and the mass spectra were obtained using the ion trap operating in a SIM scan mode.

For expression of NCS serum values in this paper absolute values are used in $\mu \mathrm{mol} / \mathrm{l}$, as well as in $\mu \mathrm{mol} / \mathrm{l}$ 
divided by total cholesterol in $\mathrm{mmol} / \mathrm{l} \times 100$ as ratios, which according to Miettinen and Kempen better express the true NCS balance $[12,13]$.

The study was approved by the $\mathrm{Na}$ Homolce Hospital Ethical Committee as part of Project No. NA 7452-3 supported by the Internal Grant Agency of the Czech Ministry of Health (IGA MZ CR).

\section{Statistical Analysis}

Statistical analysis was performed using MedCalc Version 8.1.1. 1 (Belgium). The basic statistical parameters included mean or median calculation $(95 \%$ $\mathrm{Cl})$, number of elements in sample, maximum and minimum values, and relevant standard deviations. The normal distribution of the set was tested using the D'Agostino-Pearson test. For graphical comparison of patient groups Box-and-Whisker plots were used with the median and 25-75 percentil.
Paired t-test was used to compare the two independent means of NCS measured values and lipid metabolites during treatment. The difference was significant with values $<0.05$

\section{RESULTS}

The individual cohorts of the children and adolescents under survey are basically characterized in Table 1. The average NCS results for the group of 84 healthy school-age children used as reference values are given in Table 2. Values for the healthy subjects are dominated by Cam, followed by Sit, while Lat and Des levels are lower. Despite the slightly lower levels in the youngest children, there is not much variance in the overall values between the healthy children and healthy adults.

Table 2: Reference Values of Noncholesterol Sterols in 84 Healthy Children and 25 Healthy Adults ( $\mu$ mol/l)

\begin{tabular}{|c|c|c|c|c|}
\hline & Lathosterol & Desmosterol & Campesterol & Sitosterol \\
\hline \multicolumn{5}{|l|}{$6-8 y r s$} \\
\hline girls & $4.0+/-0.8$ & $2.6+/-0.5$ & $9.9+/-1.2$ & $7.4+/-0.9$ \\
\hline boys & $3.7+/-0.9$ & $2.2+/-0.6$ & $9.7+/-1.4$ & $7.5+/-1.1$ \\
\hline \multicolumn{5}{|l|}{$8-12 y r s$} \\
\hline girls & $6.0+/-0.6$ & $3.2+/-0.4$ & $11.0+/-1.0$ & $7.7+/-0.7$ \\
\hline boys & $6.0+/-0.6$ & $3.3+/-0.4$ & $9.7+/-0.9$ & $7.2+/-0.7$ \\
\hline \multicolumn{5}{|l|}{ 12-15yrs } \\
\hline girls & $7.2+/-0.5$ & $3.8+/-0.3$ & $10.5+/-0.7$ & $7.0+/-0.5$ \\
\hline boys & $6.1+/-0.5$ & $3.5+/-0.3$ & $9.6+/-0.8$ & $7.0+/-0.6$ \\
\hline \multicolumn{5}{|l|}{ 15-18yrs } \\
\hline girls & $5.7+/-0.8$ & $3.1+/-0.5$ & $10.1+/-1.2$ & $5.8+/-0.9$ \\
\hline boys & $6.3+/-1.3$ & $3.3+/-0.8$ & $16.0+/-2.0$ & $7.4+/-1.5$ \\
\hline \multicolumn{5}{|c|}{ adults $18-65 y$ rs } \\
\hline women & $6.4+/-0.7$ & $4.2+/-0.4$ & $10.7+/-1.0$ & $8.7+/-0.8$ \\
\hline men & $7.4+/-1.1$ & $3.9+/-0.6$ & $9.1+/-1.6$ & $7.7+/-1.2$ \\
\hline
\end{tabular}

Table 3: Average Plasmatic Levels of NCS in Healthy Children Compared with LCHD Treated Patiens Suffering from HFH

\begin{tabular}{|c|c|c|c|c|c|}
\hline & & Lat & Des & Cam & Sit \\
\hline & Number & $\mu \mathrm{mol} / \mathrm{l}$ & $\mu \mathrm{mol} / \mathrm{l}$ & $\mu \mathrm{mol} / \mathrm{l}$ & $\mu \mathrm{mol} / \mathrm{l}$ \\
\hline \multicolumn{6}{|c|}{ Healthy children } \\
\hline girls & 52 & $4.8+/-0.4$ & $2.8+/-0.2$ & $9.3+/-0.7$ & $6.2+/-0.5$ \\
\hline boys & 32 & $4.6+/-0.5$ & $2.4+/-0.3$ & $9.4+/-0.9$ & $6.4+/-0.6$ \\
\hline \multicolumn{6}{|c|}{ Children on lowcholesterol diet $(300 \mathrm{mg} / \mathrm{d})$} \\
\hline girls & 25 & $11.1+/-1.2$ & $5.3+/-0.7$ & $11.7+/-1.9$ & $7.3+/-1.4$ \\
\hline boys & 23 & $7.7+/-1$ & $4.5+/-0.6$ & $11.6+/-1.7$ & $9.2+/-1.2$ \\
\hline t-test & & $\mathrm{p}<0.0001$ & $p<0.0001$ & $p<0.0001$ & $p<0.0001$ \\
\hline
\end{tabular}


Children with $\mathrm{HFH}$ who have been on longitudinal LCHD, with which they often arrive at the outpatient lipid clinic, have higher levels of Lat and Des; Cam and Sit are also increased because the mothers usually enrich the LCHD with plant sterol margarines (Table 3, Figure 2a, 2b).

In the group of children with documented LDL-R mutations, the increase in Lat and Des is greater than in the group of children with hypercholesterolemia where LDL-receptor deficiency has not been confirmed. Statins administrated in effective doses reduce TCh as well as Lat and Des levels (Figure 3). Alterations of both in absolute values correlate with the TCh lowering response $(p<0.001)$. It is only when statin doses are too low that the Lat level persists or falls slowly

Doses of statin can be individually set for each patient according to the intensity of its Lat levels decrease. Compensatory increase of Cam and Sit has
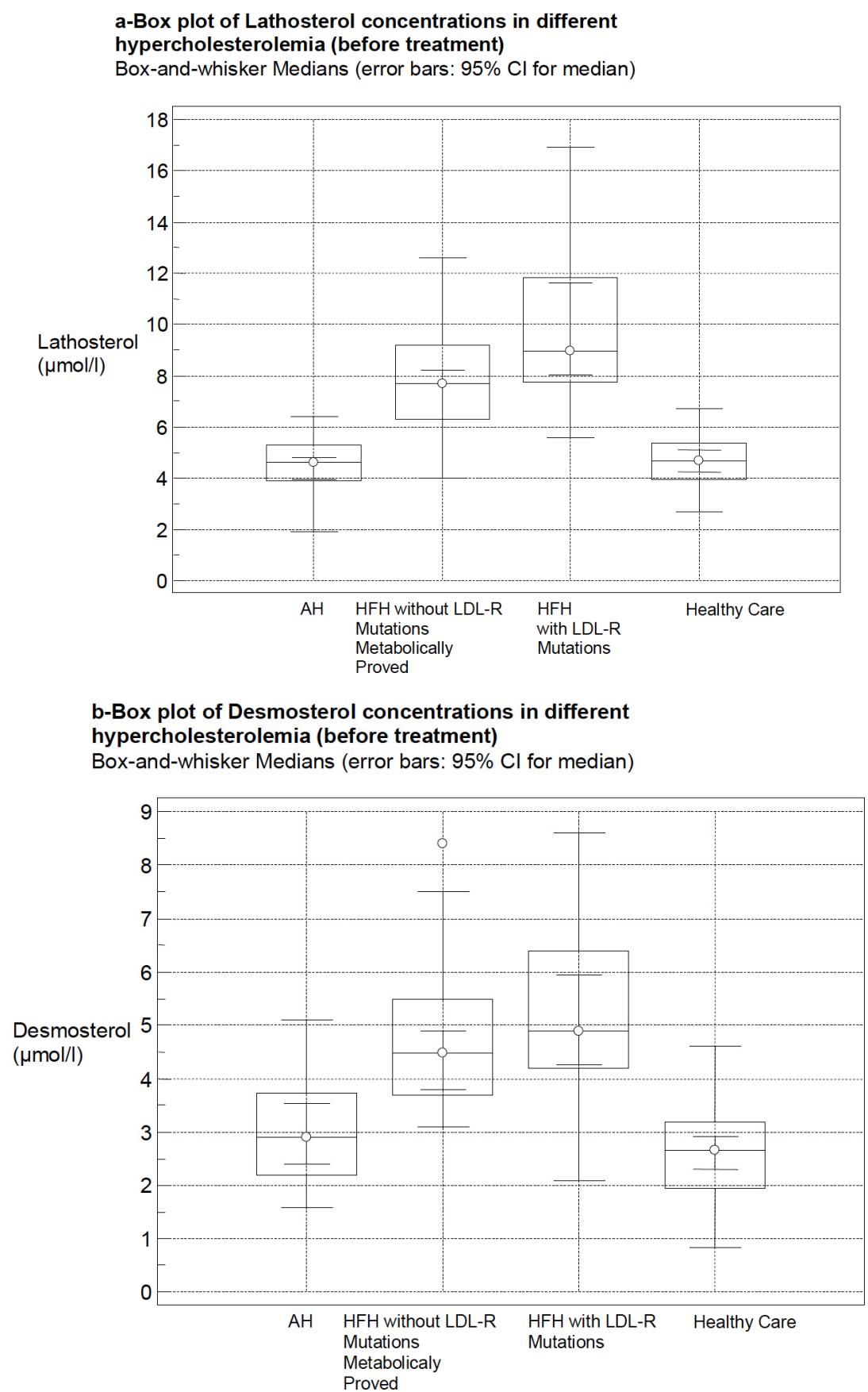

Figure 2: a) Box plot of lathosterol concentrations in different hypercholesterolemias (before treatment). b) Box plot of desmosterol concentrations in different hypercholesterolemias (before treatment). 


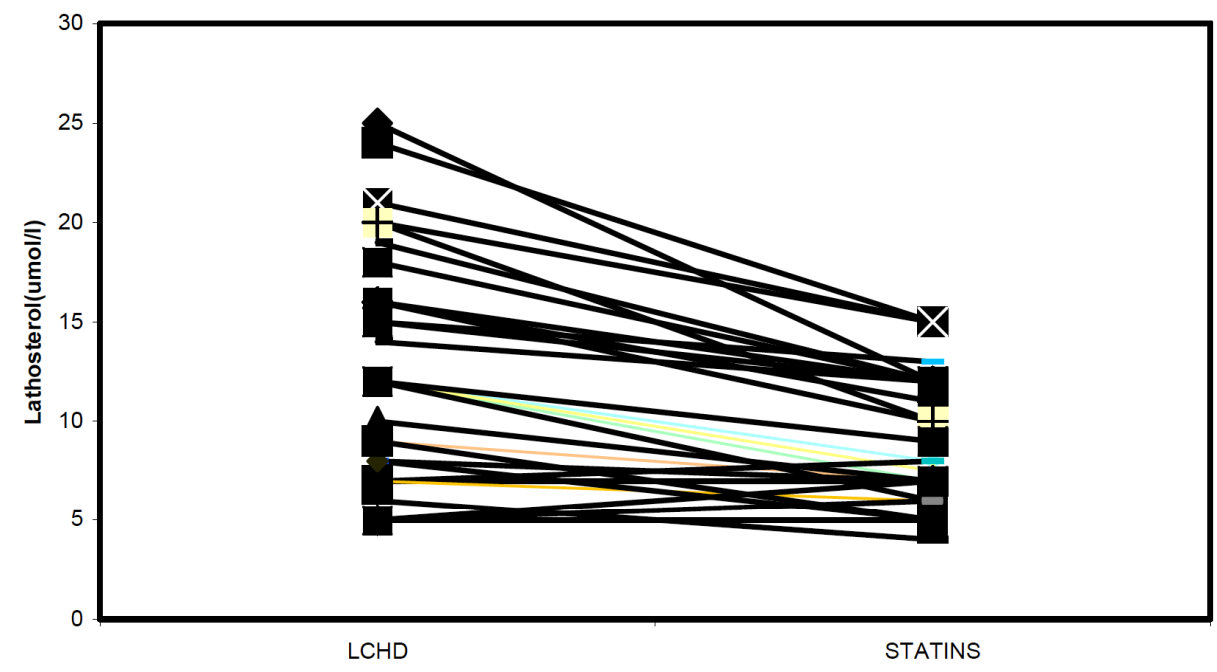

Figure 3: Lathosterol decrease after interruption of LCHD and introduction of statin therapy in patients with HFH.

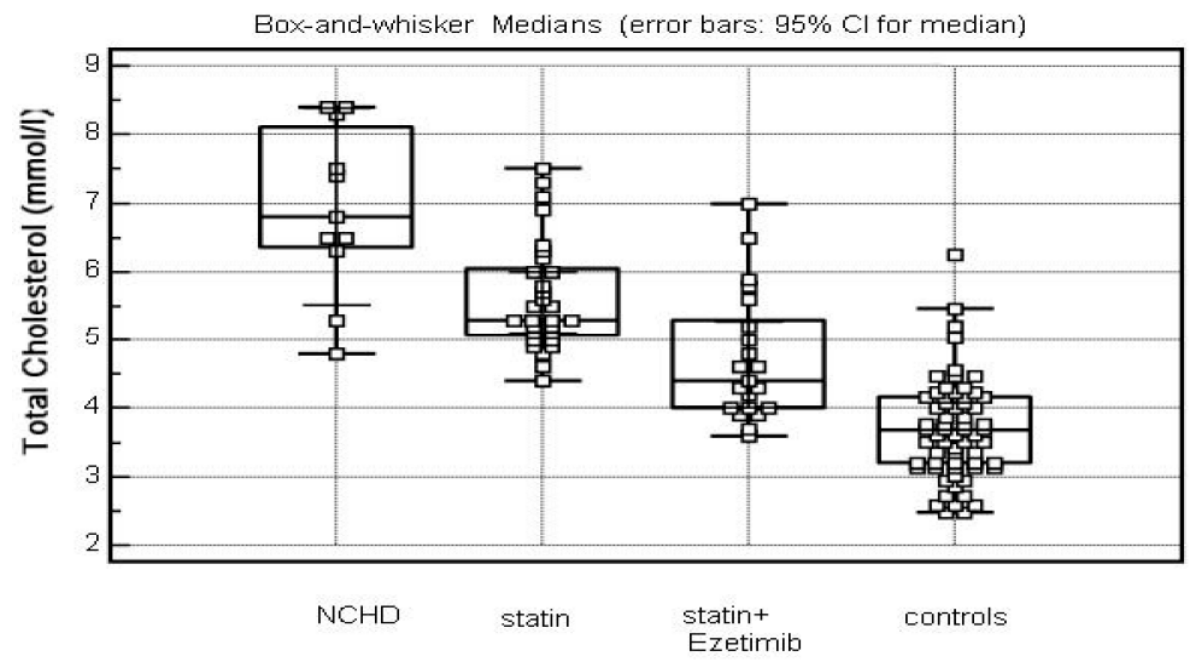

a

Box-and-whisker Medians (error bars: $95 \% \mathrm{Cl}$ for median)

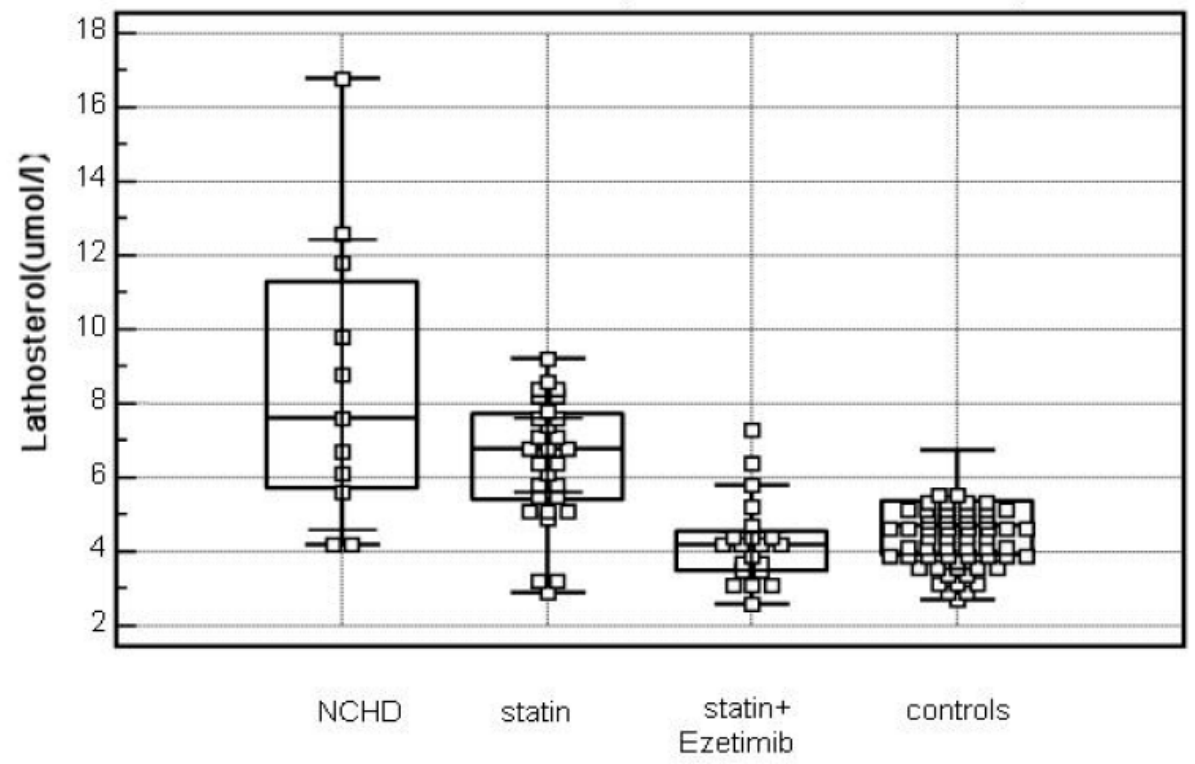


(Figure 4). Continued.

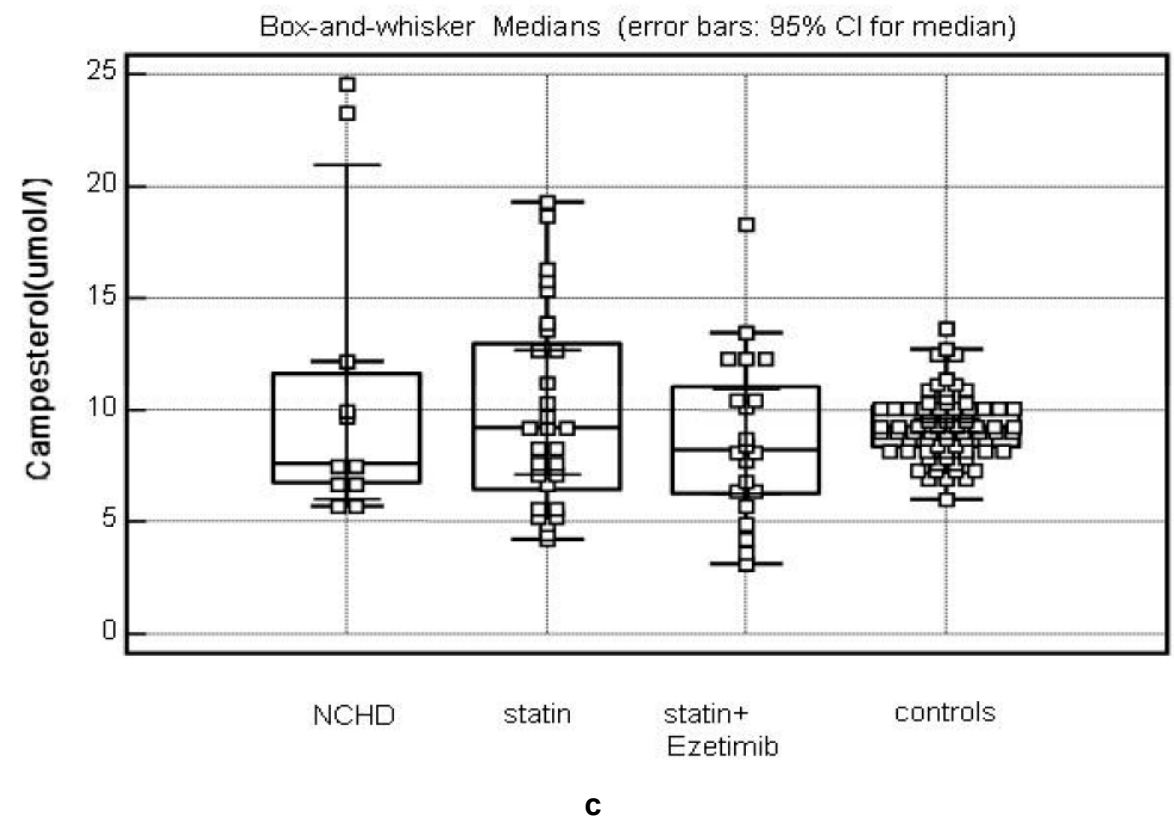

Figure 4: a) Box plot of cholesterol concentrations in hypercholesterolemias according to the type od dietary or medical treatment.

b) Box plot of lathosterol concentrations in hypercholesterolemias according to the type of dietary or medical treatment.

c) Box plot of campesterol concentrations in hypercholesterolemias according to the type of dietary or medical treatment.

only been observed in few patiens. Combined treatment of statin with ezetimibe has to date produced the most effective decrease in both Lat and Des along with decreased TCh, while the Cam and Sit are also reduced (Figure $\mathbf{4 a}, \mathbf{4 b}, \mathbf{4 c}$ ).

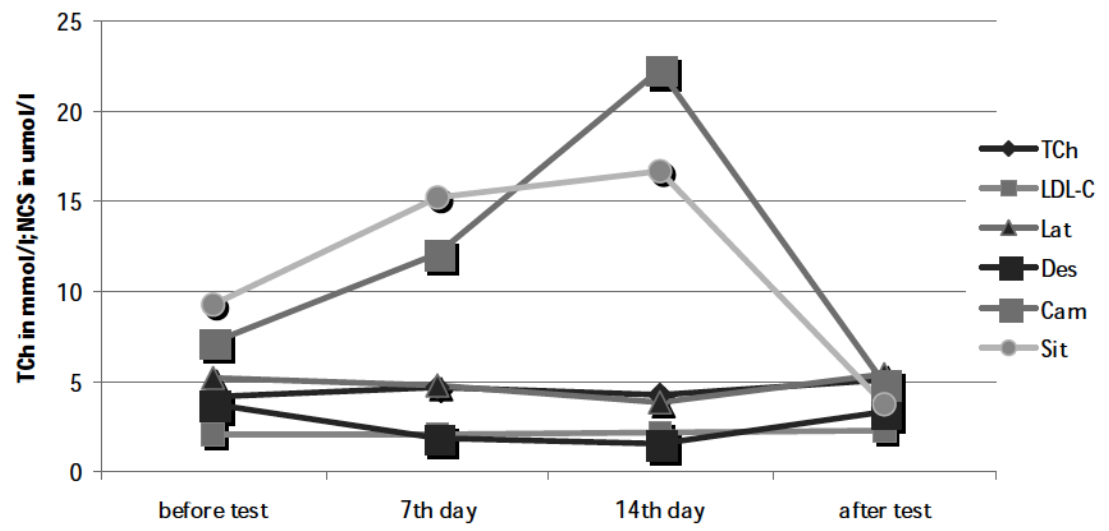

Figure 5: Loading test with phytosterol enriched margarine in a stabilized HFH patient.

Table 4: Noncholesterol Sterols in (a) 37 Children with AH and (b) 38 Children with HFH

\begin{tabular}{|c|c|c|c|}
\hline NCS & a) Median (+/-SD) & b) Median (+/-SD) & (Significance (p<) \\
\hline \hline Lat $(\mu \mathrm{mol} / \mathrm{l})$ & $4.6+/-0.93$ & $8.95+/-2.7$ & 0.0001 \\
\hline Lat/TChx100 & $92.0+/-18.6$ & $129+/-63.2$ & 0.0011 \\
\hline Cam $(\mu \mathrm{mol} / \mathrm{l})$ & $8.6+/-2.5$ & $7.7+/-5.1$ & 0.3786 \\
\hline Cam/TChx100 & $168+/-47.5$ & $117+/-103$ & 0.0211 \\
\hline Des $(\mu \mathrm{mol} / \mathrm{l})$ & $2.9+/-0.89$ & $4.9+/-1.69$ & 0.0011 \\
\hline Des/TChx100 & $92+/-18$ & $59+/-22$ & 0.1469 \\
\hline Sit $(\mu \mathrm{mol} / \mathrm{l})$ & $6.3+/-2.4$ & $6.0+/-3.6$ & 0.6898 \\
\hline Sit/TChx100 & $104+/-49$ & $74+/-45$ & 0.025 \\
\hline
\end{tabular}




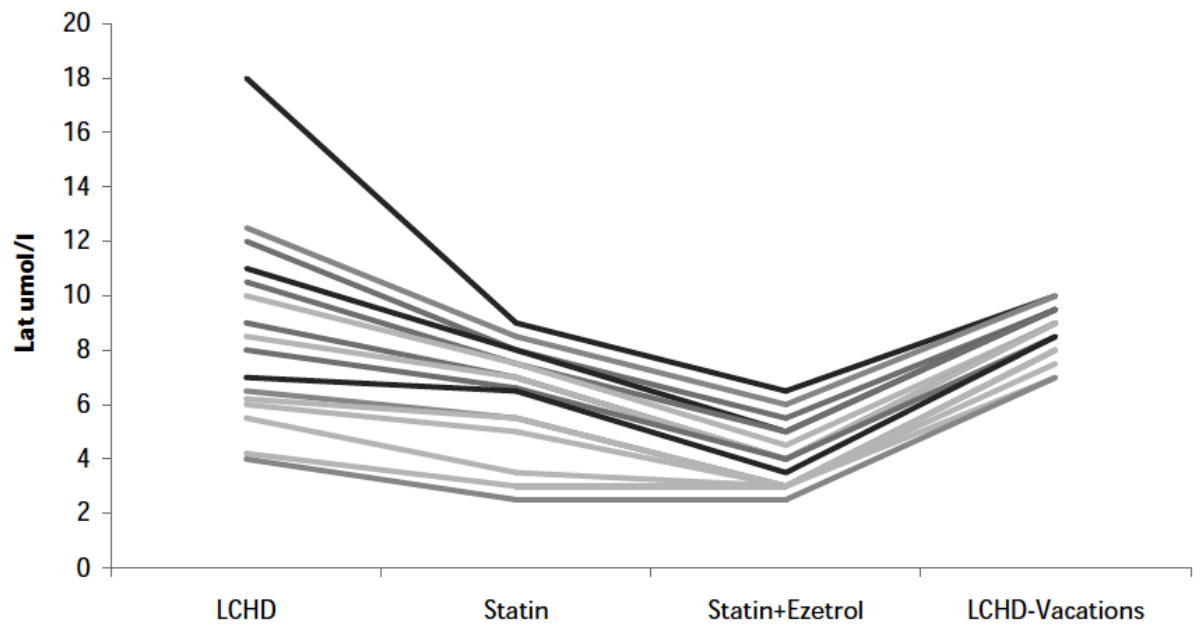

Figure 6: Monitoring of lathosterol levels in children with HFH on LCHD and differentiated drug treatment when carefully monitored also during vacations.

Ingesting plant sterol-enriched margarines such as Flora Pro Active (Unilever) 20g/d raises Cam and Sit levels and the intensity of dietary supplementation can be controlled in this way (Figure 5).

Children with $\mathrm{AH}$ do not have elevated levels of Lat, Des compared to HFH (Table 4, Figure 2a, 2b).

In 30 child patients we could observe the "typical changes" in plasmatic Lat levels where the LCHD and targeted drug therapy were applied as shown in the graph in Figure 6.

Our explanation is that during vacations the children are often without proper parental control for drug treatment, and thus usually only the LCHD is observed, which results in immediate Lat level increase.
Example of typical curves for Lat and other NCS during dietary and medical treatment in a 12-year homozygous female patient with FDB are shown in Figure 7.

\section{DISCUSSION}

Every doctor working in a lipid clinic certainly has experience with the failure of LCHD in the treatment of $\mathrm{HFH}$ even when the parents comply with this treatment. We have all also encountered strict mothers or grandmothers who apply even stricter LCHD $(200 \mathrm{mg} / \mathrm{d})$ than necesssary (leading more often than not to protein deficiency) trying to protect their children from the risk of the vascular failure they have experienced among their closest relatives, and whose attempts result in reduced growth as indicated by the children's growth

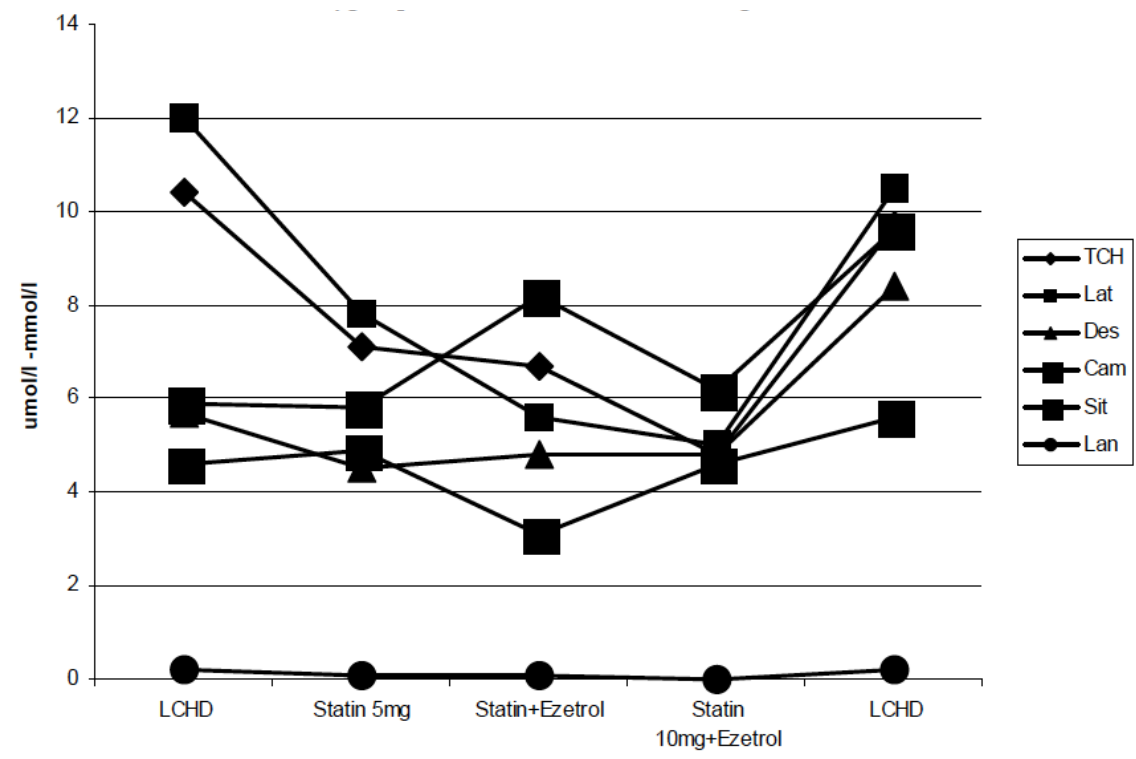

Figure 7: Monitoring of NCS plasmatic levels in a homozygous patient with FDB mutation during dietary and drug treatment. 
curves. On the other hand, we see gullible mothers, and especially grandmothers, accompanying typically "overfed children" with TCh and TAG levels of 8-12 $\mathrm{mmol} / \mathrm{l}$, who only follow television advertising or clamorous leaflets offering "guaranteed" dietary products from domestic and foreign companies. We have therefore enlarged the range of markers for the differential diagnosis of hypercholesterolemias in order to simplify the system as much as possible and avoid harming the children.

A lot has been publicized about metabolism, physiological and pathobiochemical findings of NCS, esp. in connection with CVD, but little research is still available on the practical experience with its daily use $[21,23,25]$. In our decision-making concerning treatment in our clinic we have been so far most helped by Lat levels. The compensatory increase of Cam and Sit in statin therapy postulated by Miettinen, Descamps, Sudhop, Santosa, Hedman and al. [17, 18, $21,22,33,34$ ] have been observed only in few patients because the doses of statin used in combined therapy with ezetimibe in our children were mostly below 20 $\mathrm{mg} / \mathrm{d}$. However, some children cannot be clearly classified as belonging to any of the above mentioned groups based upon their first metabolic evaluation, and they maintain enormously high Lat values or high Cam values during various types of treatment. These are probably the types of patients described a long time ago by Katan et al. as "hyperresponders or hyporesponders" [35].

However, we do agree with the recommendation of Miettinen et al. that effective statin therapy is mainly observed in the "synthetizer" type patients with high levels of Lat and Des, whereas ezetimibe treatment is more effective in the "absorber" type patients with high Cam and Sit. [17-19, 21, 23]. The combination of ezetimibe and statin is the most effective and least intrusive form of medical treatment, which fully corresponds with Sudhop's observations [36]. LCHD continues to be reserved primarily for $\mathrm{AH}$, as well as for patients with mixed dyslipidemia, where no molecular genetic examination is yet available or the lipid laboratory spectrum does not allow for successful differentiation.

The possible correlation between low cholesterol synthesis of Lat and high absorption of Cam as seen by Weingartner and other authors in patiens proving the high risk of CVD could not be assessed in our children patiens with $\mathrm{HFH}[17,37,38,39]$.
It should be noted that phytosterols are also atherogenic substances and their increased intake is just as harmful to our health as high levels of cholesterol $[40,41]$

Given the existence of around 1,000 known mutations of LDL-Rs with different functional capacities for cholesterol internalization (from 5 to $70 \%$ ) and also given the proven influence of other risk factors, such as high Lp (a) $>1000 \mathrm{mg} / \mathrm{l}$, or adverse polymorphism of apo $E 3 / 4$ and $4 / 4$, it is not at all surprising to find such a wide range of hypercholesterolemic patients with diverse reactions to any treatment. The sample size of patients appearing too small to give such cathegorical conlusions, however, it will be necessary in the future to increase the number of patients, complete the methodology, compare practical experience, standardize the testing and verify the observations of different authors so that the discovered value of NCS can really be of practical daily use to clinic doctors, as recommended by MacKay, Thompson et al. [39, 42, 43].

\section{CONCLUSION}

Evaluation of NCS in the lipid outpatient clinic is of practical use:

$0 \quad$ in the differentiation of familial heterozygous hypercholesterolemia and alimentary hypercholesterolemia;

$0 \quad$ in determining the size of therapeutic statin doses;

$0 \quad$ in monitoring effective medication (monotherapy or combined therapy);

- for checking whether the patient is actually taking the recommended medication and for verification of the actual intake of food enriched with plant sterol esters.

\section{CONFLICT OF INTERESTS}

All te authors declare that there is no conflict of interest that could be perceveid as prejudicing the impartiality of the research reported.

\section{ACKNOWLEDGEMENTS}

Dr. Hyanek reports receiving research support from Thermo Fisher Scientific s.r.o., Prague. 


\section{ABBREVIATIONS}

$$
\begin{array}{ll}
\text { ApoB } & =\text { apolipoprotein } \mathrm{B} \\
\mathrm{AH} & =\text { alimentary hypercholesterolemia } \\
\text { Cam } & =\text { campesterol } \\
\mathrm{CVD} & =\text { cardiovascular disorders } \\
\text { Des } & =\text { desmosterol } \\
\text { FDB } & =\text { familial ligand- defective apoB } 100 \\
\mathrm{HFH} & =\text { heterozygous familial } \\
&
\end{array}
$$$$
\mathrm{GC} / \mathrm{MS}=\text { gas chromatography/mass spectrometry }
$$$$
\text { IMT = intima media thickness }
$$$$
\text { Lat } \quad=\text { lathosterol }
$$$$
\text { LCHD = low-cholesterol diet }
$$$$
\text { LDL-Ch = low density lipoprotein cholesterol }
$$$$
\operatorname{Lp}(a) \quad=\text { lipoprotein }(a)
$$$$
\text { NCEP }=\text { National Cholesterol Education Program }
$$
(USA)

NCS $=$ non-cholesterol sterols

LDL-R = LDL-cholesterol receptor

Sit $=$ sitosterol

TAG $=$ triacylglycerols

TCh $=$ total cholesterol

\section{REFERENCES}

[1] Expert panel on integrated guidelines for cardiovascular health and risk reduction in children and adolescents. Pediatrics 2011; S 213-S256

[2] Magnussen CG, Venn A, Thomson R, et al. The association of pediatric low-density lipoprotein cholesterol and highdensity lipoprotein cholesterol dyslipidemia classifications and change in dyslipidemia satus with carotid intimal-media thickness in adulthood evidence from the cardiovascular risk in Young Finns Study, the Bogalusa Heart Study, and the CDAH (Childhood Determinants of Adult Health) Study. J Am Coll Cardiol 2009; 53: 860-69.

http://dx.doi.org/10.1016/j.jacc.2008.09.061

[3] McCrindle BW, Urbina EM, Dennison BA, et al. Drug therapy of high-risk lipid abnormalities in children and adolescents: a specific statement from the American Heart Association Atherosclerosis, Hypertension and Obesity in Youth Committee, Council of Cardiovascular Disease in the Young, with the Council on Cardiovascular Nursing. Circulation 2007; 115: 1948-67.

http://dx.doi.org/10.1161/CIRCULATIONAHA.107.181946
Gidding SS, Dennison BA, Birch LL, et al. Dietary recommendations for children and adolescents: a guide for practitioners: consensus statement from the American Heart Association. Circulation 2005; 112: 2061-75.

http://dx.doi.org/10.1161/CIRCULATIONAHA.105.169251

deJongh S, Ose L, Szamosi T, Gagne C, Lambert M, et al. Efficacy and safety of statin therapy in children with familial hypercholesterolemia: a randomized, double-blind, placebo controlled trial with simvastatin. Circulation 2002; 106: 223137.

\section{http://dx.doi.org/10.1161/01.CIR.0000035247.42888.82}

Wiegman A, Hutten BA, deGroot E, et al. Efficacy and safety of statin therapy in children with familial hypercholesterolemia: a randomized controlled trial. JAMA 2004; 292: 33137.

http://dx.doi.org/10.1001/jama.292.3.331

[7] Rodenburg J, Vissers MN, Wiegman A, et al. Statin treatment in children with familial hypercholesterolemia. The younger, the better. Circulation 2007; 116: 664-68. http://dx.doi.org/10.1161/CIRCULATIONAHA.106.671016

[8] Avis HJ, Hutten BA, Gagné V, et al. Efficacy and safety of rosuvastatin therapy for children with familial hypercholesterolemia. J Am Coll Cardiol 2010; 55: 1121-26. http://dx.doi.org/10.1016/j.jacc.2009.10.042

[9] Gauer R. Hyperlipidemia treatment in children: The younger, the better. Am Family Physician 2010; 82: 462-77.

[10] Clauss S, Wai KM, Kavey RW, Kuehl K. Ezetimibe treatment of pediatric patients with hypercholesterolemia. J Pediat 2009; 154: 869-72 http://dx.doi.org/10.1016/j.jpeds.2008.12.044

[11] Health Regulations-Preventive Screenings. Bulletin of the Czech Ministry of Health, 7/1994 (in Czech).

[12] Miettinen TA. Cholesterol precursors and thein diurnal rhytm in lipoproteins of patients with jejunoileal bypass and ileal dysfunction. Metabolism 1985; 34: 425-30. http://dx.doi.org/10.1016/0026-0495(85)90207-0

[13] Kempen HJM, Glaatz JFC, Leuven JAG, et al. Serum lathosterol concentration is an indicator of whole-body cholesterol synthesis in humans. J Lipid Res 1988; 29: 114955

[14] Miettinen TA, Tilovbis RS, Kesaniemi YA. Serum plant sterols and cholesterol precursors reflect cholesterol absorption and synthesis in volonteers of a randomly selected male population. Am J Epidemiol 1990; 131: 20-31.

[15] Jones PJ, Schoelleer DA. Evidence for diurnal periodicity in human cholesterol synthesis. J Lipid Res 1990; 312: 667-73.

[16] Hamilton JJ, Hany M, Innis SM. Elevation of plasma lathosterol, as indicator of increased cholesterol synthesis in preterm infants given Intralipid. Pediat Res 1992; 31: 186-92. http://dx.doi.org/10.1203/00006450-199202000-00020

[17] Miettinen TA, Gylling H, Strandberg TE, et al. for Finish 4S Investigators. Baseline serum cholestanol as predictor of recurrent coronary events in subgroups of Scandinavian Simvastatin Survival Study. Br Med J 1998; 316: 1127-30. http://dx.doi.org/10.1136/bmj.316.7138.1127

[18] Miettinen TA, Gylling H. Synthesis and absorption markers of cholesterol in serum and lipoproteins during a large dose of statin treatment. Eur J Clin Invest 2003; 33: 967-82. http://dx.doi.org/10.1046/j.1365-2362.2003.01229.x

[19] Gylling $H$. Cholesterol metabolism and its implications for therapautic interventions in patients with hypercholesterolemia. Int J Clin Practice 2004; 58: 859-66. http://dx.doi.org/10.1111/j.1742-1241.2004.00351.x

[20] Gylling $\mathrm{H}$, Miettinen TA. The effect of plant stanol- and sterolenriched foods on lipid metabolism, serum lipids and coronary heart disease. Ann Clin Biochem 2005; 42: 254-63. http://dx.doi.org/10.1258/0004563054255605 
[21] Hedman M, Miettinen TA, Gylling H, Ketomäki A, Antikainen M. Serum noncholesterol sterols in children with heterozygous familial hypercholesterolemia undergoing pravastatin therapy. J Pediat 2006; 148: 241-46. http://dx.doi.org/10.1016/j.jpeds.2005.08.068

[22] Santosa S, Varady KA, AbuMweis S, Jones P. Physilogical and therapeutic factors affecting cholesterol metabolism; Does a reciprocal relationship between cholesterol absorption and synthesis really exist? Life Sci 2007; 80: 50514.

http://dx.doi.org/10.1016/j.Ifs.2006.10.006

[23] Nissien MJ, Miettinen TE, Gylling $H$, Miettinen TA. Applicability of noncholesterol sterols in predicting response in cholesterol metabolism to simvastatin and fluvastatin treatment among hypercholesterolemic men. Nutr Metab Cardiovasc Dis 2010; 20: 308-16.

http://dx.doi.org/10.1016/j.numecd.2009.04.014

[24] Assman GK, Kannenberg DR, Ramey TA, et al. Effects of ezetimibe, simvastatin, atorvastatin, and ezetimibe-statin therapies on non-cholesterol sterols in patients with primary hypercholesterolemia. Curr Med Res Opin 2008; 24: 249-59. http://dx.doi.org/10.1185/030079908X253663

[25] Noto D, Cefalu ABC, Barraco $G$, et al. Plasma noncholesterol sterols: a useful diagnostic tool in pediatric hypercholesterolemia. Pediatr Res 2010; 67: 200-204. http://dx.doi.org/10.1203/PDR.0b013e3181c8f035

[26] NCEP Expert panel of blood cholesterol levels in children and Adolescents. National Cholesterol Education Program (NCEP): Highlights of the Report of the Expert Panel on Blood Cholesterol Levels in Children and Adolescents. Pediatrics, 1992, 89, 495-501. American Academy of Pediatrics. Statement on Cholesterol. Committee on Nutrition. Pediatrics, 1992, 90, 469-473. The population approach: nutrition recommendations for healthy children and adolescents. Pediatrics 1992; 89: 537-44.

[27] Hyánek J, Martiníková $V$, Mat'oška $V$, et al. 10 years experience with medical treatment of familial hypercholesterolemia in children and adolescents. Českoslov. Pediatrie 2006; 61: 404-412. (in Czech with English summary).

[28] Rifkind BM, Segal P. Lipid research clinic program reference values for hyperlipidemia and hypolipidemia. JAMA 1983; 250: 1869-72. http://dx.doi.org/10.1001/jama.1983.03340140039025

[29] Tanner JM. Growth and Adolescence, $2^{\text {nd }}$ ed. Oxford, Blackwell UK 1962.

[30] Francova H, Trbusek M, Zapletalova P, et al. New promoter mutations in the low-density lipoprotein receptor gene which induce familial hypercholesterolemia phenotype. Molecular and functional analysis. J Inher Metab Dis 2004; 27: 523-28. http://dx.doi.org/10.1023/B:BOLI.0000037337.93335.c4

[31] Phillips KM, Ruggio DM, Bailey JA. Precise quantitative determination of phytosterols, stenols, and cholesterol metabolites in human serum, by capillary gas-liquid chromatography. J Chromatog 1999; B732: 17-29. http://dx.doi.org/10.1016/S0378-4347(99)00257-1

[32] Theunissen CE, Regente J, Bergman K, et al. Serum cholesterol precursors and metabolites and cognitive performace in an aging population. Neurobiol Aging 2003; 24: $147-55$.

http://dx.doi.org/10.1016/S0197-4580(02)00061-1

[33] Descamps OS, DeSutter J, Guillaume M, Missault L. Where does the interplay between cholesterol absorption and synthesis in the context of statin and/or ezetimibe treatment stand today? Atherosclerosis $2011 ; 217$ : 308-21. http://dx.doi.org/10.1016/j.atherosclerosis.2011.06.010

[34] Sudhop T, Reber M, Tribble D, et al. Changes in cholesterol absorption and cholesterol synthesis caused by ezetimibe and/or simvastatin in men. J Lipid Res 2009; 50: 2117-23. http://dx.doi.org/10.1194/jlr.P900004-JLR200

[35] Katan MB, Beynen AC. Characteristics of human hypo- and hyperresponders to dietary cholesterol. Am J Epidemiol 1987; 126: 387-99.

[36] Sudhop T, Gottwald BM, Bergman K. Serum plant sterols as a potential risk factor for cardiovascular disease. Metabolism 2002; 51: 1514-21. http://dx.doi.org/10.1053/meta.2002.36298

[37] Sutherlanbd WHF, Williamns MJA, Nye NJ, Restieaux NJ, deJong SA, Walker HL. Associations of plasma noncholesterol sterol levels with severity of coronary artery disease. Nutr Metab Cardiovasc Dis 1998; 8: 389-91.

[38] Weingartner O, Lutjohann D, Vanmierlo T, et al. Markers of enhanced cholesterol absorption are a strong predictor for cardiovascular diseases in patiens without diabetes mellitus. Chem Phys Lipids 2011; 164: 451-56.

http://dx.doi.org/10.1016/j.chemphyslip.2011.03.008

[39] MacKay DS, Johes PJH. Plasma noncholesterol sterols: current uses potential and need for standardization. Curr Opin Lipidol 2012; 23: 241-47. http://dx.doi.org/10.1097/MOL.0b013e328353292e

[40] Sudhop T, Gottwald BM, Begmann K. Serum plant sterol as a potential risk factor for cardiovascular disease. Metabolism 2002; 51: 1514-21. http://dx.doi.org/10.1053/meta.2002.36298

[41] Assmann G, Cullen P, Ertey $\mathrm{J}$, et al. Elevation in plasma sitosterol concentration is associated with an increased risk for coronary events in the Procam Study. Circulation 2003; 108(Suppl.): 3300.

[42] MacKay D, Jones PJH. Evaluation of methods for the determination of cholesterol absorption and synthesis in humans. Atherosclerosis 2011; 218: 253-62.

http://dx.doi.org/10.1016/j.atherosclerosis.2010.04.022

[43] Thompson GR, O Neil FO, Seed M. Why some patients respond poorly to statins and how this might be remedied. Eur Heart J 2002; 23: 200-206. http://dx.doi.org/10.1053/euhj.2001.3071

[44] Folch J, Lees M, Sloane Stanley GHS. A simple method for the isolation and purification of total lipides from animal tissues. J Biol Chem 1957; 226: 497-509.

[45] Thompson RH, Merola GV. A simplified alternative to the AOAC official method for cholesterol in multi-component food. AOAC Int 1993; 76: 1057-68.

[46] Hušek P. Chlormravenčnany $v$ analytické chemii jako činidla rychlé esterifikace. [Chloroformates in analytical chemistry as reagent of rapid esterification; available only in Czech]. Unpublished PhD thesis 1996.

(C) 2014 Hyanek et al.; Licensee Lifescience Global.

This is an open access article licensed under the terms of the Creative Commons Attribution Non-Commercial License (http://creativecommons.org/licenses/by-nc/3.0/) which permits unrestricted, non-commercial use, distribution and reproduction in any medium, provided the work is properly cited. 